\title{
Video Capsule Endoscopy in a Patient with a Billroth II Gastrectomy and Obscure Bleeding
}

We report a case of obscure gastrointestinal bleeding in a 68-year-old man who was admitted to hospital with melena. In the past he had undergone a Billroth II gastrectomy for duodenal ulcer. Since then he had experienced several episodes of gastrointestinal bleeding. Esophagogastroduodenoscopies, push enteroscopy, ileocolonoscopies, small-bowel barium enema, angiographic computed tomography, and blood pool scintigraphy were all performed, but the bleeding source was never found.

It was suspected that the source of the bleeding was the small intestine and M2A video capsule endoscopy (Given Imaging Ltd., Yoqneam, Israel) was requested [1-3]. After the patient swallowed the video capsule, duodenoscopy (Olympus TJF-160; Olympus, Hamburg, Germany) was performed under radiological control, in order to identify the afferent and efferent loops. A guide wire was left in the afferent loop as a marker (Figure 1). The capsule was easily identified in the gastric stump and was grasped with a foreign body forceps (Figure 2). With the video capsule held in this position, the endoscope was carefully pushed forward in the efferent loop, where the video capsule was released. The correct position of the capsule was confirmed radiographically. There were no technical problems and no complications. The capsule identified potential bleeding sources: the patient was found to have diffuse areas of angiodysplasia in the small bowel which were not suitable for surgical treatment.

This report describes a novel technique that may overcome some of the possible obstacles to the use of video capsule endoscopy, such as previous gastroduodenal surgery. By using an endoscope and a foreign-body forceps, it was even possible to perform this examination in a patient who had undergone a Billroth II gastrectomy, thus providing useful information on the possible source of bleeding. We agree with other authors $[4,5]$ who suggest that major abdominal surgery, in it-

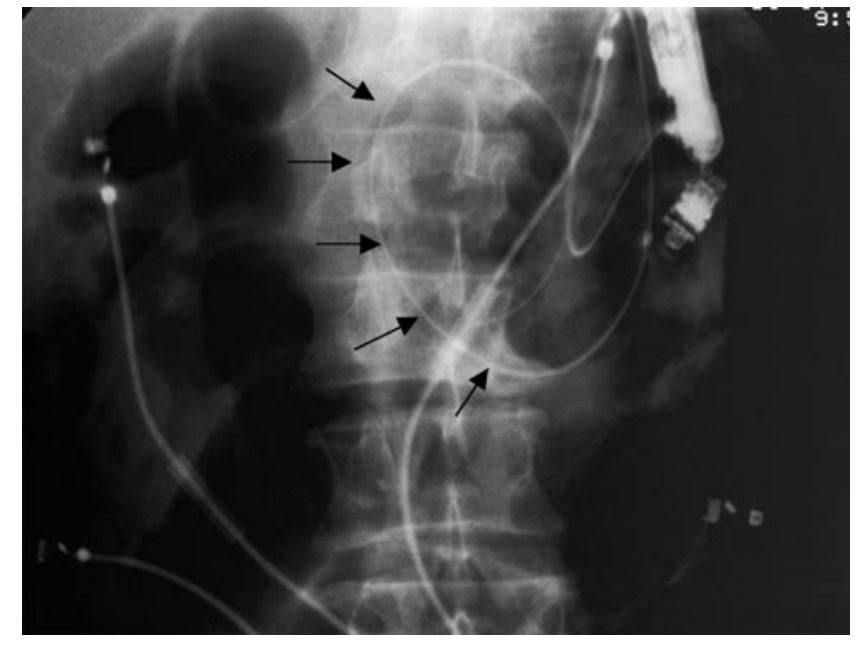

Figure 1 A duodenoscope was used to identify the afferent and efferent loops. A guide wire was left in the afferent loop as a marker (arrows).

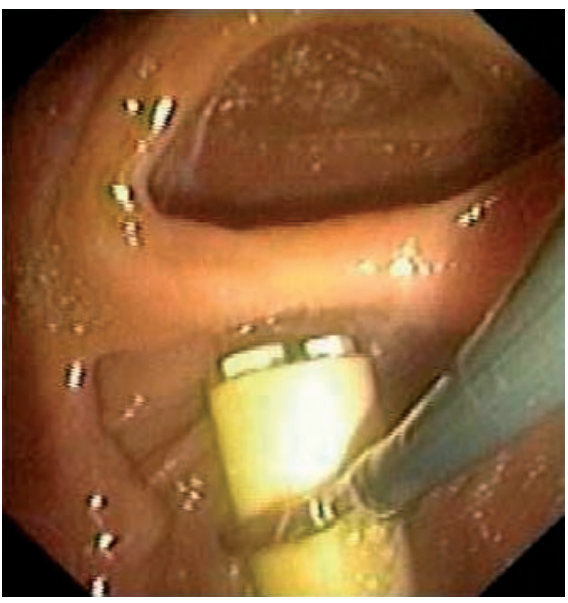

Figure 2 The video capsule was easily identified in the gastric stump, where it was grasped with a foreign-body forceps before being pushed forward in the efferent loop.

self, should not be considered an absolute contraindication for capsule endoscopy.

\section{G. Spera, C. Spada, M. E. Riccioni, V. Perri, G. Costamagna \\ Digestive Endoscopy Unit, Catholic} University, Rome, Italy

\section{References}

${ }^{1}$ Appleyard M, Fireman Z, Glukhovsky A et al. A randomized trial comparing wireless capsule endoscopy with push enteroscopy for the detection of smallbowel lesions. Gastroenterology 2000; 119: $1431-1438$
${ }^{2}$ Costamagna G, Shah SK, Riccioni ME et al. A prospective trial comparing small bowel radiographs and video capsule endoscopy for suspected small bowel disease. Gastroenterology 2002; 123: 999-1005

${ }^{3}$ Ell C, Remke S, May A et al. The first prospective controlled trial comparing wireless capsule endoscopy with push enteroscopy in chronic gastrointestinal bleeding. Endoscopy 2002; 34: 685689

${ }^{4}$ Scapa E, Jacob H, Lewkowicz S et al. Initial experience of wireless-capsule endoscopy for evaluating occult gastrointestinal bleeding and suspected small bowel pathology. Am J Gastroenterol 2002; 97: 2776-2779

${ }^{5}$ Hollerbach S, Kraus K, Willert J et al. Endoscopically assisted video capsule endoscopy of the small bowel in patients with functional gastric outlet obstruction. Endoscopy 2003; 35: 226-229

\section{Corresponding Author}

\section{G. Costamagna, M.D.}

Digestive Endoscopy Unit, Catholic University

Largo A. Gemelli 8 • 00168 Rome · Italy

Fax: $\quad+39-06-30156581$

E-mail: gcostamagna@rm.unicatt.it 